TULIP

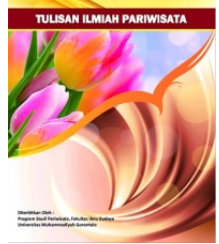

TULIP: Tulisan Ilmiah Pariwisata

E-ISSN: 2720-9873

Available Online at https://journal.umgo.ac.id/index.php/Tulip/index

Vol. 3, No. 2 Desember 2020

DOI: http://dx.doi.org/10.31314/tulip.3.2.42-48.2020

\title{
KAJIAN PENGGUNAAN KRITERIA DAN INDIKATOR GSTC SEBAGAI INSTRUMEN PENILAIAN PEMBANGUNGAN PARIWISATA BERKELANJUTAN BERBASIS LINGKUNGAN
}

Irma Charisma Hatibie, ${ }^{1}$ Srilian Laxmiwaty Dai, ${ }^{2}$ Anggraini M.S Lagalo, ${ }^{3}$

Program Studi Pariwisata, Universitas Muhammadiyah Gorontalo, Indonesia

Email;1.irma@umgo.ac.id,2.1yanlaxmiwaty@umgo.ac.id,3.anggraenims@umgo.ac.id

\begin{tabular}{ll}
\hline Info Artikel & Abstract: \\
Diterima: 20 & The tourism sector is built based on development that prioritizes welfare, \\
Mei 2020 & especially for people in rural areas. Not only as a sector that can provide an \\
& economic boost but at the same time providing a sense of security against \\
& concerns over the overexploitation of natural resources. Therefore, as part of \\
Disetujui: 02 & the process in the management of a tourism destination, it requires an in-depth \\
Juni 2020 & study of instruments that can assist tourism destination management in \\
& assessing the environmental resilience crisis. This instrument is needed to \\
& reduce environmental impacts, which are currently feared to damage the \\
& environment around the destination. One of the instruments used in this \\
& research is the criteria and indicators of the Global Sustainable Tourism Council \\
& (GSTC). The method of this research used a descriptive qualitative method, \\
& comparative analysis (implementation and indicators).The result of this \\
& research is Tunggul Arum rural tourism destination does not fulfill the \\
& environmental-based on GSTC criteria and indicators.
\end{tabular}

Keywords: Indikator GSTC, Desa Wisata, Pembangunan Pariwisata, Tunggul Arum.

\begin{abstract}
Abstrak:
Sektor pariwisata dibangun berdasarkan pembangunan yang mengutamakan kesejahteraan, terutama bagi masyarakat di pedesaan. Tidak hanya sebagai sektor yang dapat memberikan dorongan ekonomi tetapi sekaligus memberikan rasa aman terhadap kekhawatiran eksploitasi sumber daya alam yang berlebihan. Oleh karena itu, sebagai bagian dari proses dalam pengelolaan suatu destinasi pariwisata, diperlukan kajian mendalam terhadap instrumen-instrumen yang dapat membantu manajemen destinasi pariwisata dalam menilai krisis ketahanan lingkungan. Instrumen ini diperlukan untuk mengurangi dampak lingkungan yang saat ini dikhawatirkan merusak lingkungan sekitar destinasi. Salah satu instrumen yang digunakan dalam penelitian ini adalah kriteria dan indikator dari Global Sustainable Tourism Council (GSTC). Metode penelitian ini menggunakan metode deskriptif kualitatif, analisis komparatif (pelaksanaan dan indikator). Hasil dari penelitian ini adalah Destinasi Wisata Desa Tunggul Arum belum memenuhi kriteria dan indikator GSTC berbasis lingkungan.
\end{abstract}

Kata Kunci: Indikator GSTC, Desa Wisata, Pembangunan Pariwisata, Tunggul Arum 


\section{PENDAHULUAN}

Konsekuensi dari kegiatan pariwisata dapat menjadi salah satu faktor yang berimbas pada kerentanan isu lingungan saat ini. Kegiatan pengembangan pariwisata yang tidak diimbangi dengan memperhatikan aspek-aspek keberlanjutan lingkungan dapat berakibat fatal terhadap lingkungan itu sendiri. Dalam sebuah literatur seperti pembangunan patriwisata di Venesia yang tidak memperhatikan kebijaka dan daya dukung lingkungan dapat menimbulkan polemik pada pengelolaannya (Russo, 2002). Hal tersebut didukung oleh penelitian Cole (2012) yang mengemukakan bahwa perkembangan pariwisata di pulau Bali yang massif menyebabkan krisis air antara industri dengan masyarakat lokal terutama bagi mereka yang membutuhkan untuk keperluan pertanian. Hal ini semakin menambah urgensi dan perhatian banyak pihak bahwa pariwisata dapat memberikan dampak yang merugikan bagi lingkungan itu sendiri.

Sektor pariwisata dibangun atas dasar pembangunan yang mengedepankan kesejahteraan terutama masyarakat di daerah perdesaan. Bukan hanya sebagai sektor yang dapat memberikan peningkatan ekonomi, namun disaat yang bersamaan memberikan rasa aman terhadap kekhawatiran pada ekploitasi sumber daya alam yang berlebihan. Oleh karena itu, sebagai bagian dari proses dalam manajemen sebuah destinasi pariwisata, maka dibutuhkan kajian mendalam tentang instrument yang dapat membantu pihak manajemen destinasi wisata dalam menilai krisis ketahanan lingkungan. Instrument ini dibutuhkan untuk mereduksi dampak lingkungan yang pada saat ini dikhawatirkan dapat merusak lingkungan di sekitar destinasi.

Salah satu instrumen yang dapat digunakan dalam mengukur kerentanan isu lingkungan pada sektor pariwisata adalah kriteria dan indikator Global Sustainable Tourism Council (GSTC). Kriteria dan indikator ini memiliki beberapa poin yang dapat digunakan untuk menilai dan mengevaluasi destinasi wisata berdasarkan empat pilar utama pembangunan pariwisata berkelanjutan. salah satu dari pilar yang diambil sebagai rujukan dalam mengukur kerentanan lingkungan dalam penelitian ini adalah pilar nomor empat yaitu "Memaksimalkan manfaat untuk lingkungan dan meminimalkan dampak negatif".

Indikator dan kriteria pada setiap kategori yang ditawarkan adalah pilar keempat dari GSTC sesuai dengan standar kebijakan yang dikeluarkan oleh UNWTO dan dapat digunakan sebagai alat untuk mengukur ketersediaan sarana dan prasarana kegiatan pembangunan pariwisata yang berorientasi pada lingkungan (GSTC, 2013). Seperti yang diusulkan oleh Kementrian Pariwisata dan Ekonomi Kreatif, mengenai percepatan pembangunan pariwisata berkelanjutan, yaitu pembangunan yang meemperhatikan lingkungan, sosial, budaya ekonomi untuk masa kini dan masa yang akan datang (Kemenparekraf, 2020). Pembangunan ini pula sejalan dengan kebutuhan akan pemberdayaan masyarakat lokal dan wisatawan.

Penelitian terdahulu di desa wisata Kembang Arum dalam hal penggunaan kriteria dan indikator GSTC belum pernah dilakukan. Terutama pada aspek penggunaan alat yang berhubungan dengan isu kerentanan lingkungan. Penggunaan kriteria dan indikator ini diharapkan dapat memberikan wawasan dan pendekatan baru terhadap kebutuhan akan media yang digunakan atau alat ukur yang aplikatif pada pembangunan pariwisata berkelanjutan. Oleh karena itu, tujuan dari penelitian ini adalah 
menjawab tantangan isu kerentanan lingkungan pada suatu destinasi menggunakan salah satu kriteria dan indikator GSTC.

Metode penelitian yang digunakan adalah metode deskriptif kualitatif, analisis komparatif (implementasi dan indikator). Tujuan dari metode ini adalah untuk mengemukakan hasil penelitian berdasarkan pokok tujuan, yaitu sejauh mana penerapan pengembangan desa wisata Kembang Arum dan Tunggul Arum dijalankan, berdasarkan kriteria yang telah disusun dalam GSTC (Global Sustainable Tourism Council). Hasil penelitian dari meodologi penelitian kualitatif digambarkan selalu terbuka untuk persoalan baru, dan sesuai dengan pandangan subyektif mengenai realitas sosial (Mulyana, 2004).

Alat pengumpulan data yang digunakan adalah menggunakan kuesioner. Untuk memudahkan dalam menganalisis data, maka variabel-variabel yang digunakan diukur dengan mempergunakan model skala likert, yang diberi tiga kategori, yaitu YA, Tidak Tahun, dan Tidak. Dalam penelitian ini, data primer merupakan data yang akan dideskripsikan secara kualitatif, pengumpulan data tersebut berbentuk kuesioner yang dijadikan dasar wawancara dengan responden yang telah ditunjuk. Pengambilan data yang bersifat satu arah ini tidak menampilkan hubungan secara langsung antara responden dengan masyarakat karena disesuaikan dengan rujukan kriteria dan indikator GSTC.

\section{HASIL DAN PEMBAHASAN}

Kriteria GSTC merupakan upaya minimum yang perlu dicapai oleh setiap organisasi dalam destinasi wisata untuk mempertimbangkan keberlanjutan destinasi pariwisata (Batari, 2018). Dari hasil penelitian menunjukan, setiap indikator memiliki tiga kriteria penilaian yaitu YA,
Tidak Tahu, dan TIDAK. Keterpenuhan dari kriteria dan indikator setiap bagian akan mempengaruhi dari banyaknya jawaban antara YA dan TIDAK. Berikut adalah tabel kriteria dan indikator Memaksimalkan manfaat bagi lingkungan, dan meminimalkan dampak negatif.

Tabel 1 Kriteria dan Indikator GSTC Terkait isu Lingkungan

\begin{tabular}{|c|c|c|c|}
\hline No & Pertanyaan & 1 & 2 \\
\hline D.1.a & $\begin{array}{lr}\text { Penilaian } & \text { keberlanjutan } \\
\text { destinasi untuk } & 5 \text { tahun } \\
\text { terakhir } & \text { telah } \\
\text { teridentifikasi risikonya } & \text { rikn } \\
\text { terhadap lingkungan }\end{array}$ & & $\sqrt{ }$ \\
\hline D.1.b & $\begin{array}{l}\text { Sistem penanganan risiko } \\
\text { telah tersedia }\end{array}$ & & $\sqrt{ }$ \\
\hline D.2.a & $\begin{array}{l}\text { Melaksanakan dan } \\
\text { memperbaharui } \\
\text { inventarisasi habitat dan } \\
\text { margasatwa yang sensitif } \\
\text { dan terancam punah. }\end{array}$ & & $\sqrt{ }$ \\
\hline D.2.b & $\begin{array}{l}\text { Sistem pengelolaan untuk } \\
\text { memonitor dampak dan } \\
\text { melindungi ekosistem, } \\
\text { lingkungan dan spesies } \\
\text { yang sensitif }\end{array}$ & & $\sqrt{ }$ \\
\hline D.2.c & $\begin{array}{l}\text { Sistem untuk mencegah } \\
\text { masuknya spesies asing } \\
\text { (invasive) }\end{array}$ & & $\sqrt{ }$ \\
\hline D.3.a & $\begin{array}{l}\text { Convention } \\
\text { International Trade in } \\
\text { Endangered Species of Wild } \\
\text { Fauna and Flora (CITES) }\end{array}$ & & $\sqrt{ }$ \\
\hline D.3.b & $\begin{array}{lr}\text { Peraturan dan } & \text { standar } \\
\text { untuk } & \text { mengontrol } \\
\text { perburuan } & \text { atau } \\
\text { penangkapan, } & \\
\text { memamerkan dan menjual } \\
\text { flora dan fauna }\end{array}$ & & $\sqrt{ }$ \\
\hline D.4.a & $\begin{array}{lr}\text { Program } & \text { pendampingan } \\
\text { untuk } & \text { membantu } \\
\text { perusahaan } & \text { dalam } \\
\end{array}$ & & $\sqrt{ }$ \\
\hline
\end{tabular}




\begin{tabular}{|c|c|c|c|}
\hline & $\begin{array}{l}\text { mengukur, memonitor, } \\
\text { meminimalkan dan } \\
\text { melaporkan kepada public } \\
\text { mengenai emisi gas rumah } \\
\text { kaca }\end{array}$ & & \\
\hline D.4.b & 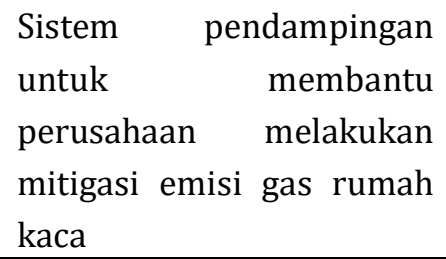 & & $\sqrt{ }$ \\
\hline D.5.a & $\begin{array}{lr}\text { Program } & \text { untuk } \\
\text { mempromosikan } & \text { dan } \\
\text { mengukur } & \text { konservasi } \\
\text { energi, } & \text { memonitor, } \\
\text { mengurangi } & \text { serta } \\
\text { melaporkan } & \text { konsumsi } \\
\text { energy kepada publik }\end{array}$ & & $\sqrt{ }$ \\
\hline D.5.b & $\begin{array}{l}\text { Kebijakan dan insentif } \\
\text { untuk mengurangi } \\
\text { ketergantungan bahan } \\
\text { bakar fosil, meningkatkan } \\
\text { efisiensi energi dan } \\
\text { mendorong adopsi serta } \\
\text { penggunaan teknologi } \\
\text { energi terbarukan }\end{array}$ & & $\sqrt{ }$ \\
\hline D.6.a & $\begin{array}{lr}\text { Program } & \text { pendampingan } \\
\text { untuk } & \text { membantu } \\
\text { perusahaan } & \text { dalam } \\
\text { mengukur, } & \text { memonitor, } \\
\text { mengurangi } & \text { dan } \\
\text { melaporkan } & \text { penggunaan } \\
\text { air } & \\
\end{array}$ & & $\sqrt{ }$ \\
\hline D.7.a & $\begin{array}{l}\text { Sistem pengelolaan untuk } \\
\text { memastikan bahwa air } \\
\text { yang digunakan oleh } \\
\text { perusahaan dan yang } \\
\text { dibutuhkan } \\
\text { masyarakat lokal telah } \\
\text { seimbang dan sesuai } \\
\end{array}$ & $\sqrt{ }$ & \\
\hline D.8.a & $\begin{array}{l}\text { Sistem pengelolaan untuk } \\
\text { memonitor dan } \\
\text { melaporkan kualitas air } \\
\text { minum dan rekreasi }\end{array}$ & & $\sqrt{ }$ \\
\hline
\end{tabular}

\begin{tabular}{|c|c|c|}
\hline & kepada publik & \\
\hline D.8.b & $\begin{array}{l}\text { Hasil monitoring tersedia } \\
\text { untuk publik }\end{array}$ & $\sqrt{ }$ \\
\hline D.8.c & $\begin{array}{l}\text { Sistem untuk menanggapi } \\
\text { isu kualitas air dengan } \\
\text { tepat }\end{array}$ & $\sqrt{ }$ \\
\hline D.9.a & $\begin{array}{l}\text { Peraturan dalam } \\
\text { penempatan, } \\
\text { pemeliharaan } \\
\text { pengujian isi septic tank } \\
\text { dan sistem pengolahan } \\
\text { limbah cair, serta bukti } \\
\text { tindakan penegakannya }\end{array}$ & $\sqrt{ }$ \\
\hline D.9.b & $\begin{array}{l}\text { Peraturan } \\
\text { memastikan ukuran dan } \\
\text { jenis pengolahan limbah } \\
\text { cair yang sesuai untuk } \\
\text { lokasi tersebut dan bukti } \\
\text { tindakan penegakannya }\end{array}$ & $\sqrt{ }$ \\
\hline D.9.c & $\begin{array}{lr}\text { Program } & \text { pendampingan } \\
\text { untuk } & \text { membantu } \\
\text { perusahaan } & \text { dalam } \\
\text { mengolah } & \text { dan } \\
\text { menggunakan } & \text { kembali } \\
\text { limbah cair secara efektif }\end{array}$ & $\sqrt{ }$ \\
\hline D.9.d & $\begin{array}{l}\text { Program untuk } \\
\text { memastikan pengolahan } \\
\text { limbah yang baik, aman } \\
\text { untuk digunakan kembali } \\
\text { atau dibuang dengan efek } \\
\text { kerugian yang minimal } \\
\text { bagi warga lokal dan } \\
\text { lingkungan }\end{array}$ & $\sqrt{ }$ \\
\hline D.10.a & $\begin{array}{lr}\text { Sistem } & \text { pengumpulan } \\
\text { limbah padat dilakukan } \\
\text { dengan mencatat jumlah } \\
\text { limbah yang dihasilkan }\end{array}$ & $\sqrt{ }$ \\
\hline D.10.b & $\begin{array}{l}\text { Perencanaan pengelolaan } \\
\text { limbah padat yang } \\
\text { diterapkan, memiliki } \\
\text { tujuan kuantitatif untuk } \\
\text { meminimalkan dan } \\
\text { memastikan pembuangan }\end{array}$ & $\sqrt{ }$ \\
\hline
\end{tabular}




\begin{tabular}{|c|c|c|}
\hline & $\begin{array}{l}\text { secara aman dan } \\
\text { berkelanjutan, serta tidak } \\
\text { digunakan kembali } \\
\text { maupun didaur ulang }\end{array}$ & \\
\hline D.10.c & $\begin{array}{l}\text { Program untuk membantu } \\
\text { perusahaan mengurangi, } \\
\text { menggunakan kembali dan } \\
\text { mendaur ulang limbah } \\
\text { padat }\end{array}$ & $\sqrt{ }$ \\
\hline D.10.d & $\begin{array}{l}\text { Program untuk } \\
\text { mengurangi penggunaan } \\
\text { botol air kemasan plastik } \\
\text { oleh perusahaan dan } \\
\text { pengunjung }\end{array}$ & $\sqrt{ }$ \\
\hline D.11.a & $\begin{array}{l}\text { Panduan dan peraturan } \\
\text { untuk meminimalkan } \\
\text { polusi cahaya dan suara }\end{array}$ & $\sqrt{ }$ \\
\hline D.11.b & $\begin{array}{lr}\text { Program } & \text { pendampingan } \\
\text { untuk } & \text { mendorong } \\
\text { perusahaan } & \text { mengikuti } \\
\text { panduan dan peraturan } & \\
\text { dalam } & \text { meminimalkan } \\
\text { polusi cahaya dan suara }\end{array}$ & $\sqrt{ }$ \\
\hline D.12.a & $\begin{array}{lr}\text { Program } & \text { untuk } \\
\text { meningkatkan penggunaan } \\
\text { transportasi ramah } \\
\text { lingkungan }\end{array}$ & $\sqrt{ }$ \\
\hline D.12.b & $\begin{array}{l}\text { Program untuk membuat } \\
\text { pengunjung tertarik } \\
\text { menggunakan transportasi } \\
\text { aktif (seperti berjalan kaki } \\
\text { dan bersepeda) }\end{array}$ & $\sqrt{ }$ \\
\hline
\end{tabular}

Sumber: GSTC, 2013

Hasil analisis dari semua indikator pada bagian $\mathrm{D}$ dengan total sub indikator berjumlah 28 adalah jawaban hampir keseluruhan indikator yang terjawab TIDAK. Kriteria dan indikator yang hanya dijawab YA yaitu Sistem pengelolaan untuk memastikan bahwa air yang digunakan oleh perusahaan dan yang dibutuhkan oleh masyarakat lokal telah seimbang dan sesuai. Dengan demikian dapat diketahui bahwa desa wisata Tunggul
Arum tidak memenuhi kriteria dan indikator GSTC tersebut, dengan bobot pertanyaan hanya terjawab $<50 \%$ dari total keseluruhan sub pertanyaan.

Secara teori desa wisata Tunggul Arum masuk dalam kategori desa wisata, yang menyebutkan bahwa; desa wisata didefinisikan sebagai suatu wilayah pedesaan yang menawarkan keseluruhan suasana yang mencerminkan keaslian desa, baik dari segi kehidupan sosial budaya, dan struktur tata ruang desa, serta potensi yang mampu dikembangkan sebagai daya tarik wisata, misalnya: atraksi, makanan dan minuman, cinderamata, penginapan, dan kebutuhan wisata lainnya (Fandeli, 2002). Teori lainnya menyebutkan bahwa; desa wisata adalah suatu wilayah pedesaan yang menawarkan keaslian baik dari segi sosial budaya, adatistiadat, keseharian, arsitektur, tradisional, sturuktur tata ruang desa yang disajikan dalam suatu bentuk integrasi komponen pariwisata antara lain seperti atraksi, akomodasi, dan fasilitas pengunjung (Darsono; 2005, Ahimsa, 2010). Maka jika dilihat dari ciri-ciri desa wisata berdasarkan teori diatas, Kembang Arum dan Tunggul Arum; masuk dalam kategori desa wisata.

\section{Menuju "Desa Wisata" Berkelanjutan}

Sebuah pengembangan desa wisata semestinya menerapkan pendekatan community based tourism, yang menitikberatkan peran penting masyarakat dalam menunjang pembangunan pariwisata. Sedangkan keterlibatan pemerintah dan swasta sebatas memfasilitasi masyarkat sebagai pelaku utama pengembangan desa wisata (Raharjana, 2012, Damanik, 2017). Wacana tentang desa wisata merupakan wacana yang belum sepenuhnya didasarkan pada temuan-temuan empiris yang berasal dari penelitian lapangan yang cukup seksama dan mendalam (Ahimsa, 2010). Wacana yang dimaksud adalah eksistensi desa wisata 
sebagai sesuatu yang "diinginkan" atau yang "seharusnya" ada, tetapi belum membicarakan desa wisata sebagaimana desa tersebut ditemui dalam kehidupan seharihari, dengan seribu-satu macam persoalannya (Damanik, 2009; Firdaus, 2007; Sumadi, 2010; Ahimsa, 2010). Dari hasil penelitian ini, ditemukan bahwa masalah yang sering dihadapi adalah kelembagaan dari struktur organisasi pengelola destinasi wisata. hal ini dapat dilihat dari hasil wawancara dengan Dinas Pariwisata Kabupaten Sleman, sebagai berikut;

"Kriteria dari desa disebut desa wisata dilihat dari peran masyarakat itu sendiri. Salah satunya adalah kelembagaan, yang dilihat struktur organisasi. Kami telah menetapkan 8 indikator penilaian untuk melihat pengelolaan desa wisata itu berkembang. Jikalau dari indikator tidak dipenuhi maka itu dapat dinaikkan atau diturunkan statusnya"

(Responden, Pemerintah DISPAR Kab Sleman)

Asas keberlanjutan oleh lembaga besar dunia seperti UNWTO menyebutkan bahwa "All Countries should have clearly articulated tourism policies and strategies that embrace the principles of sustainable tourism" (UNWTO, 2012). Hal ini menunjukan bahwa setiap destinasi seharusnya memperhitungkan langkah membangun pariwisata berkelanjutan beberapa tahun kedepan. Tantangan yang dihadapi oleh beberapa daerah terpencil adalah jika sebuah destinasi tidak dikelola dengan baik, maka dikhawatirkan destinasi tersebut tidak akan mampu bertahan dengan pesaingnya. Akibatnya, pembangunan yang mengalami resesi akan berdampak pula pada kredibilitas suatu destinasi, penurunan tingkat kepercayaan wisatawan dan sulit bertahan ketika krisis melanda.

Peran masyarakat itu penting, oleh karenanya, peran pengembangan destinasi di suatu wilayah tidak dapat mengabaikan peran dari masyarakat itu sendiri. Hasil penelitian ini memperlihatkan bahwa salah satu desa masih berpegang pada asas pengelolaan destinasi secara kelembagaan dengan menunjuk pengelola desa wisata sebagai bagian dari organisasi kelembagaan yang ikut bertanggungjawab dengan seluruh kegiatan desa wisata, sementara desa satunya berjalan sendiri dalam pengelolaannya, yang tidak lagi mengandalkan kelembagaan dan peran masyarakat.

\section{KESIMPULAN}

Dalam melakukan penelitian tentunya masih ada kekuarangan dan batasan yang perlu untuk diperbaiki atau ditambahkan. Tidak terkecuali dalam penelitian ini. Beberapa kendala lainnya yang masih ditemukan peneliti, misalnya; waktu penelitian yang masih dirasa kurang, karena untuk mengevaluasi suatu destinasi dengan mencocokan kriteria dan indikator GSTC yang sangat banyak butuh upaya ke beberapa lembaga pariwisata setempat, tak hanya dari dinas pariwisata saja, tapi juga dari beberapa dinas lain, misalnya dari Dinas Lingkungan Hidup.

Tantangan lainnya dalam penelitian ini adalah banyaknya pertanyaan indikator GSTC disesuaikan dengan masalah kebutuhan oleh destinasi. Bagi desa wisata yang ada di Kabupaten Sleman, tentu ini merupakan tantangan untuk mendapatkan pengakuan destinasi yang telah sesuai dengan indikator ini agar tetap bertumbuh dan bersaing dengan destinasi wisata lainnya yang berkelas dunia dan telah sesuai standar GSTC. Rekomendasi penulis adalah, agar di penelitian selanjutnya dilakukan pemilihan salah satu indikator dari 4 elemen kriteria yang telah disebutkan. Hal ini agar data yang ditemukan dapat lebih spesifik pada satu permasalahan dan kaitannya dengan 
kekauratan data. Batasan lainnya adalah dengan memilih subjek informan akan memandu peneliti dalam kemudahan pengkajian dan pengkayaan data.

Pembatasan penelitian kepada beberapa aparatur desa terutama bagi mereka yang terlibat langsung pada pengelolaan desa wisata dievaluasi kembali. Pada contoh kasus wawancara dengan Kepala Dukuh desa Tunggul Arum, ternyata beliau tidak begitu mengenal betul seperti apa SOP (Standar Operasional Prosedur) desa wisata itu berjalan. Kurangnya informasi responden yang dianggap paling mengetahui pengelolaan desa wisata, ternyata masih bingung dengan beberapa indikator pertanyaan GSTC yang berkaitan dengan program-program pengembangan. Kebingungan ini dapat dimaklumi karena beberapa desa wisata masih berupaya untuk "tetap bertahan" dengan status dalam klasifikasi desa wisata itu agar terus hidup. Hal-hal yang bersifat teknis dalam melakukan pengambilan data adalah penyederhanaan pertanyaan indikator yang lebih sederhana dan mudah dipahami oleh responden.

Beberapa tema yang berkaitan dengan penelitian ini, penulis rekomendasikan untuk menjadi penelitian lanjutan dapat dijabarkan sebagai berikut; Pertama, evaluasi terhadap SDM maupun kinerja aparat desa dalam pengembangan desa. Kedua, Evaluasi desa wisata menggunakan kriteria dan indiaktor GSTC setiap tahunnya kaitannya dengan penurunan/kenaikan klasifikasi desa wisata akan sangat menarik untuk menjadi bahan penelitian. Ketiga, Implementasi kriteria dan indikator GSTC ini sejauh mana dapat meningkatkan perekonomian desa, serta,
Keempat, peran desa wisata di Indonesia apakah mampu bersaing dengan destinasi global berdasarkan pengukuran kriteria dan indikator GSTC akan menjadi penelitian menarik selanjutnya.

\section{REFERENSI}

Ahimsa Putra, 2010., Pariwisata di Desa dan Respon Ekonomi: Kasus Dusun Brayut di Sleman, Yogyakarta. Journal: Patrawidya, Vol. 12 No 4, Hal. 635-842

Fandeli, Chafid, 2002., Perencanaan Kepariwisataan Alam, Yogyakarta: Fakultas Kehutanan UGM

Darsono, 2005., Pengertian Desa. Diunduh tanggal 12 Juni 2019 dari: http//desasentonorejo.wordpress.com /bab-ii/, Bandung: Angkasa

GSTC., Global Sustainable Tourism Council., 2013, Global Sustainable Tourism Council Criteria; Indikator Kinerja yang Disarankan Bagi Destinasi. Versi 2.0. https://www.gstcouncil.org

Soeroso, Amiluhur., 2007. Konservasi Lingkungan Kawasan Borobudur Dengan Manajemen Berbasis Pada Pembangunan Masyarakat Lokal. Jurnal: Ekonomi Pembangunan, Vol 12 (1) . hal 49-67 